\title{
A Brief Analysis on the Creation of Relaxed and Pleasant Atmosphere in the Art Class in Compulsory Education
}

\author{
Dong Guo ${ }^{1,2, *}$ \\ ${ }^{1}$ School of Humanities, Huazhong University of Science and Technology, Wuhan 430074, China \\ ${ }^{2}$ Hubei Polytechnic University, Huangshi 435003, China \\ *Corresponding author. Email: 56754431@qq.com
}

\begin{abstract}
A good, relaxed and pleasant classroom atmosphere is undoubtedly an important condition for constructing and ensuring effective learning field for teachers and students from the characteristics of the art discipline or from the perspective of receivers. In such an atmosphere, teachers can often brainstorm, fully mobilize their knowledge network and students' enthusiasm, and generate the maximum effectiveness in teaching effect. And students as receivers can also "immerse" in the learning field which is planned by teachers and jointly created by teachers and students, and obtain the greatest benefits. This paper attempts to explore how to build a relaxed and pleasant classroom atmosphere in art teaching by following methods: (1) Mobilizing students' interest in learning; (2) Applying multimedia teaching; (3) Enhancing teacher-student collaboration; (4) Giving students more thinking space.
\end{abstract}

Keywords: Art course, Atmosphere, Creating atmosphere.

\section{INTRODUCTION}

Confucius, a thinker and educator in the Spring and Autumn Period, said in The Analects, "They who love it are better than those who know it, and they who delight in it are better than those who love it." This sentence points out that the fundamental method of learning is learning for fun and learning with fun. Why emphasize the "fun" factor in the learning process? From the perspective of cognitive psychology, when an individual is in a "fun" state - a relaxed, carefree and pleasant psychological atmosphere, the cognitive process of information collection -- transformation -- encoding -output tends to reach the maximum peak. In other words, when an individual maintains a very relaxed and free state of mind, the individual is often able to enter the most efficient learning situation. This kind of atmosphere can help learners reach an emotional and mental peak. At this moment, the brain operates at high speed, thus any little hint can trigger the surge of inspiration. Obviously, art as an art form can bring people aesthetic enjoyment and happiness. In the art class, if the teacher can create a relaxed and pleasant atmosphere, coupled with the mobilization of students' emotions and thinking by pleasure of art, students' creative inspiration can be maximized. Therefore, in the teaching process, the creation of a relaxed and pleasant atmosphere should be paid more attention, which can help students free thinking space and stay in rising enthusiasm.

The traditional art teaching mode is teacher-centered, while students are the containers of knowledge. Most art teachers tend to adopt the knowledge-feeding pattern. In such a classroom atmosphere, it seems that students are listening quietly, but the actual effect is unknown. And such a teaching method makes its highly artistic knowledge becomes student's difficulty in the process of acceptance. It not only makes students hard to accept, but can only memorize by rote in accordance with the scope set by the professor, but also greatly limit the personality development of students, and they can not develop their own new areas to cultivate divergent creative thinking and ability. And teachers only "replicate" the knowledge to the students, rather than lead students to explore knowledge. This kind of teaching largely devoid of the student's personal subjective consciousness, and fail to promote their all-round development. This is not only against the spirit of "quality education", but also against the idea of "Art Curriculum Standards in Compulsory Education" issued by the Ministry of Education. Therefore, we must review and reflect on the traditional teaching method of 
art classroom in the compulsory education stage, in order to find a more effective way to solve the current dilemma. This is also the main purpose of this paper that is how to break the single and indoctrinated teaching method in the traditional art classroom? Based on years of teaching experience, combined with the comprehensive teaching theory of the new curriculum standard, and the idea that teachers are playing a leading role and students are a main body, the author believes that in the current art teaching, especially in the art class of primary and secondary schools, a relaxed, pleasant and carefree teaching atmosphere should be created. This atmosphere can be regarded as a field in which teachers and students can immerse. In this field, the maximum energy of teaching and learning can be exerted. And considering psychological and cognitive level of the primary and secondary students, this is an effective path to solve the problem of traditional art teaching. How to create a relaxed and pleasant atmosphere in the process of classroom teaching? This article clarifies this research questions from the following aspects.

\section{CONCEPT AND SIGNIFICANCE OF ART CLASSROOM ATMOSPHERE}

The preface of the "Full-time Compulsory Education Art Curriculum Standards" formulated by the Ministry of Education in 2001 states that art curriculum has a humanistic nature and is the main route for schools to conduct aesthetic education. Aesthetic education is, of course, the core idea of quality education. Therefore, in the current art education, especially in the compulsory education stage, "quality education concept" is more and more widely used in teaching practice. According to the law of students' physical and mental growth in this stage, teachers can grasp the corresponding characteristics of students displayed in this specific period. Generally speaking, students in this period have a strong curiosity for new things, a strong imitation of external things and a high degree of plasticity. In traditional classroom, students are recipients. However, under the guidance of the concept that teachers are playing a leading role and students are a main body emphasized by the new curriculum standard, how to change this resistant thinking and let students are both the recipients and active participants in learning? A very important method is to create the classroom atmosphere. Then how to understand classroom atmosphere? Atmosphere can be simply regarded as a kind of teaching classroom environment, which is jointly created by students and teachers. And it is a "field" constructed in the process of information transmission by teachers and information acceptance by students in unit time. Teachers and students will have a very energetic state due to the strong and relaxed atmosphere in the classroom. At this moment, the communication between teachers and students will achieve the best teaching effect. Because in such a spiritual collision, the students make full use of the creation of learning and teachers guide students' longing for a better life. Especially in the art classroom, the art works are often the carrier of the subjective factors such as the author's thoughts, emotions and desires. In art teaching, the main factor that guides the students to understand the confidence code hidden in the works and resonates with works is emotional guidance. And the most important and effective objective factor to implement emotional guidance is the teaching atmosphere in the art classroom. Therefore, it is important and valuable to create an art classroom atmosphere.

\section{PROBLEMS IN CREATING A PLEASANT ATMOSPHERE IN ART CLASS}

\subsection{Monotonous Teaching Method}

Students have no interest in a monotonous teaching method. Teachers' endless repetitions make students lose their interest in learning and leave students in an unitary and boring learning atmosphere. In addition, all the teaching tasks are completed according to the unified teaching materials, which have no appeal to the students, nor can they feel the charm of art. As a result, the whole learning process is lack of enthusiasm and initiative. In the art class, the teacher carries out "chalk and talk" teaching according to the traditional teaching mode, and the students can only memorize the knowledge by rote, which greatly suppresses the students' independent learning. In this process of learning, students do not exert their own emotions. And they study completely in accordance with the empty and rigid teaching mode, and fail to create their own works.

\subsection{Poor Interaction between Teachers and Students}

Teachers' serious attitude in teaching makes students feel stressed or even anxious. Students cannot diverge and extend their thoughts in this strict discipline atmosphere, and naturally they cannot achieve good expression of emotions. Because of the limited study time, in order to catch up with the teaching progress, the teacher always use every minute to impact knowledge to the students, without leaving sufficient thinking time for them. Consequently, an art class seems compact and full, but it cannot bring substantive gains to the students. Besides, in such a stressful atmosphere, students become more mechanical and dazed, thus cannot achieve the best learning effect. 


\section{COUNTERMEASURES OF CREATING A GOOD ATMOSPHERE FOR ART TEACHING}

The traditional monotonous teaching model can no longer be relied solely in art classroom, which cannot meet the needs of teaching, and fail to allow students to truly integrate into it. On the contrary, students are the main body of the classroom, and they should personally participate in the teaching. Because art, which has low requirements for logicality, is different from other disciplines. It pays more attention to the inner emotional expression, which requires the creator to generate creative passion by inspiration form people, things or situations in his/her life. And the work will be completed under this strong emotional impulse. Therefore, it is necessary to give students more space for creativity and imagination, reduce the constraints on students' thoughts and feelings as far as possible, so that their personality and creativity can be fully developed. In addition, teachers should adapt to the characteristics of teenagers in their own teaching mode, and fully activate the atmosphere of the classroom. Starting from the characteristics of the art itself, teachers should enlarge pleasure of art and apply interest teaching methods so that the students can learn the art knowledge in a happy and relaxed environment.

\subsection{Let Students Be the Protagonists}

As the inheritance and extension of art, art teaching is a dynamic teaching that changes all the time and has no fixed form. Art teachers should cultivate creative thinking of students in the learning process and ensure that each student's unique ideas can be recognized and concerned, because each student is an independent individual. Teachers should give students a stage to show their own personality and creativity, combine their works with their interest in art, and exhibit and evaluate their works. For instance, in the course of painting daffodils, students can immerse in the course by expressing their love for daffodils. Furthermore, more encouragement should be given to students, so that they can become main body of the classroom, and the enthusiasm of the students for independent in learning is aroused.

Teachers should recognize the weakness of rote teaching in the past, and re-understand the art teaching. They should bring quality education into their daily teaching, pay attention to the cultivation of students' innovative spirit and retain students' unique views and personalities. By providing students with a stage to show themselves, students can gain self-confidence in learning. Besides, teachers should mobilize the enthusiasm of students to participate in the activities and encourage every student, so that students have more enthusiasm and concentration in the future study, and a more impassioned classroom atmosphere can be created.

\subsection{Create Better Teaching Scenarios through the Application of Multimedia}

Interest in learning is of great significance to students' learning, because interest is the best teacher of students, which is more effective than the supervision and education of teachers in daily teaching. Teachers should correctly analyze the psychological characteristics and thinking modes of students, so as to make proper use of multimedia. And they should create a relaxed and interesting teaching scenarios, so as to establish a good classroom atmosphere, and promote students' interest in learning. In art courses, several specific new things can be introduced to students, who are often full of curiosity about the new concrete objects. Text, image and music can be displayed more directly through the multimedia courseware, which makes the teaching scenario more vivid. These instructional resources can construct a colorful teaching scenario for students, and achieve the audio-visual synchronization as well as static-dynamic combination. It fully mobilizes students' enthusiasm for learning, involves all students' vision and hearing to participate in and gives students the greatest experience about art courses, thus teaching efficiency is effectively improved.

\subsection{Build up a More Harmonious Teacher-Student Relationship}

Different expressions of teachers in the teaching process will affect students' learning emotions. And teachers' attitudes are internal reactions, which will directly affect students' psychology. A good attitude of teachers will make students feel more relaxed and friendly, and their interest in learning will be easier to improve. Teacher's smile will infect the students and give them a joyful hint. Excellent teachers, regardless of physical exhaustion or bad emotions, must be smiling when they enter the classroom because they can recognize the meaning of smiles. And they know that students can feel teacher's emotions and concerns, and the pleasant emotion is conducive to students' love for the course. This method will be more effective than teachers' severe criticism, so that students can fully realize the teachers' care and respect for themselves. Therefore, in the art teaching, to create a happy and harmonious atmosphere requires teachers to maintain a harmonious and friendly teaching attitude.

The art teacher should pursue the teaching goal that each student is permeated with the sweet smile in the art class, so that the student's work will be full of confidence. The teacher should first use smile to drive the students, and win the students' support and love with the charming smile. An art course in a joyful atmosphere will definitely relieve students' tension in painting. In addition to keeping a smile, teachers need to have a sense of humor. Use humor to make students laugh, 
when the students laugh, the atmosphere of the classroom will become active because of the release of students' nervousness.

\subsection{Leave Enough Thinking Space for Students}

Students' thinking about problems and knowledge directly affects the effectiveness of learning. Therefore, teachers should give full consideration to the thinking time and thinking space, and leave space for students to learn and absorb knowledge in the class. It is unwise to ignore students' self-perception just to catch up with the teaching progress. In order to truly bring substantive learning progress, no matter what kind of art problems are encountered in art classroom and how difficult the art knowledge is, teachers should encourage students to think independently. For doubts about the art course, students should be allowed to observe with problems, find specific reasons, and solve problems reasonably and effectively through their own thinking. Let students find self-confidence and satisfaction in answering questions so that students' thinking ability can be significantly enhanced.

With its continuous development, art education has a wider range of research topics. And the cultivation of a learning atmosphere in art teaching should be given more attentions. Actually, many aspects of teaching are closely related to the atmosphere, and the smooth development of teaching cannot be separated from the active and relaxed atmosphere in the classroom. In addition, good atmosphere is also guided and promoted by various factors in teaching, so the cultivation and grasp of atmosphere is necessary. In teaching process, teachers should understand its necessity, let students become the leading role of the course, and leave more time for students.

\section{CONCLUSION}

To implement arts teaching, a relaxed and pleasant atmosphere should be created so that students can learn in happiness and harvest happiness. Teachers should persist in making a reform of traditional instruction model, dare to break it and go out bravely. Through constant learning and exploration, a new art teaching class is established and make each art class full of relaxed atmosphere. And teachers need to inspire every student's artistic potential so that students really know art, love art and love life. It is not difficult to create a relaxed and pleasant classroom atmosphere in the art classroom. As long as teachers and students learn to smile in the classroom and teachers give students the opportunity to express themselves, a harmonious and pleasant classroom atmosphere will be created and finally the best effect of art teaching will be achieved.

\section{REFERENCES}

[1] Chen Bing. Education Forum [J]. Hubei Education, 2011, (04).

[2] Ernst Grosse. The Beginnings of Art [M]. The Commercial Press, 1984.

[3] Harold Osborne. The Art of Appreciation[M]. Sichuan People's Publishing House, 2006.

[4] Liu Yushan. Create a good teaching atmosphere to stimulate students' interest in learning $[\mathrm{J}]$. Learning Weekly, 2011, (28):128.

[5] Wang Wei. Effective guidance towards profundity----Reflection and Exploration on the Evaluation Language of Art Teaching [J].Jiangsu Education, 2005, (02):43-44.

[6] Wang Wei. Education for Chinese After-school [J]. Chinese Education, 2012, (17). 